\title{
TMT時代のすばる望遠鏡
}

\author{
吉田 道利 \\ 国立天文台ハワイ観測所（650 North A'ohoku Place, Hilo, Hawaii 96720, U.S.A.）
}

\section{Subaru Telescope in Thirty Meter Telescope (TMT) Era}

\author{
Michitoshi YOSHIDA \\ Subaru Telescope, National Astronomical Observatory of Japan, 650 North A'ohoku Place, Hilo, Hawaii 96720, U.S.A.
}

(Received March 11, 2018)

\begin{abstract}
The Subaru telescope, which is operated by National Astronomical Observatory of Japan, is an $8.2 \mathrm{~m}$ optical-infrared telescope at the 4,200 m summit of Maunakea, Hawaii. Its wide-field observation capability and high angular resolution make the telescope unique and one of the most powerful devices in the world. In the TMT era, wide-field capability will be particularly critical and a key characteristic of Subaru and will complement TMT's ultra-high sensitivity.
\end{abstract}

Key Words: Optical infrared astronomy, Telescope, Wide-field observation, Adaptive optics

\section{1. はじめに}

すばる望遠鏡は, アメリカ合衆国ハワイ州ハワイ島の マウナケア山頂 $($ 標高 $4,200 \mathrm{~m}$ ) に設置されている, 国立 天文台の口径8.2 mの光学赤外線望遠鏡である ${ }^{1,2}$. その 建設は1991年に開始され，1999年に完成しファーストラ イトを迎えた。科学運用・共同利用観測は2000年より始 まり，本稿執筆現在まで順調に観測を続けている。すば る望遠鏡の運用は, 1998年にハワイ州ヒロ市に設立され た国立天文台ハワイ観測所が担っている.

すばる望遠鏡の特徵は，他の8-10 m級望遠鏡にはな い広視野の観測能力と高い解像力である。TMT時代に おいては，特に，すばる望遠鏡の広視野観測能力が一つ のキーとなると考えられる。本稿では，すばる望遠鏡の 現状を概観するとともに，TMT時代にすばる望遠鏡の 果たす役割について述べる.

\section{2. すばる望遠鏡の概要}

すばる望遠鏡の外観をFig. 1 に，諸元をTable 1，2に 示す。心臓部である主鏡は, 有効径 $8.2 \mathrm{~m}$, 厚み $20 \mathrm{~cm}$ の 薄メニスカス形状の一枚鏡である。主鏡面は，平方根自 乗平均形状誤差 $12 \mathrm{~nm}$ である 口径に比して非常に薄い (アスペクト比41) 主鏡は, 261本のアクチュエータで動 的に支持されている.アクチュエータに装着された力セ ンサを用いたフィードバック制御によって主鏡形状を保 つ、TMTは分割鏡を位置制御して主鏡を支えるのに対 して，すばる望遠鏡は力制御による主鏡支持である.
全体の光学系は, リッチークレチアン系であり，主焦 点 $(\mathrm{F} / 1.83)$, カセグレン焦点 $(\mathrm{F} / 12.2)$, 左右二つのナス ミス焦点 $(\mathrm{F} / 12.6)$ のつの焦点を持つ ${ }^{1)}$. 主焦点について は，超広視野主焦点カメラHSC用の広視野補正レンズに よって直径 1.5 度の視野にわたって結像性能 0.4 秒角以下

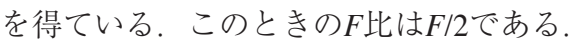

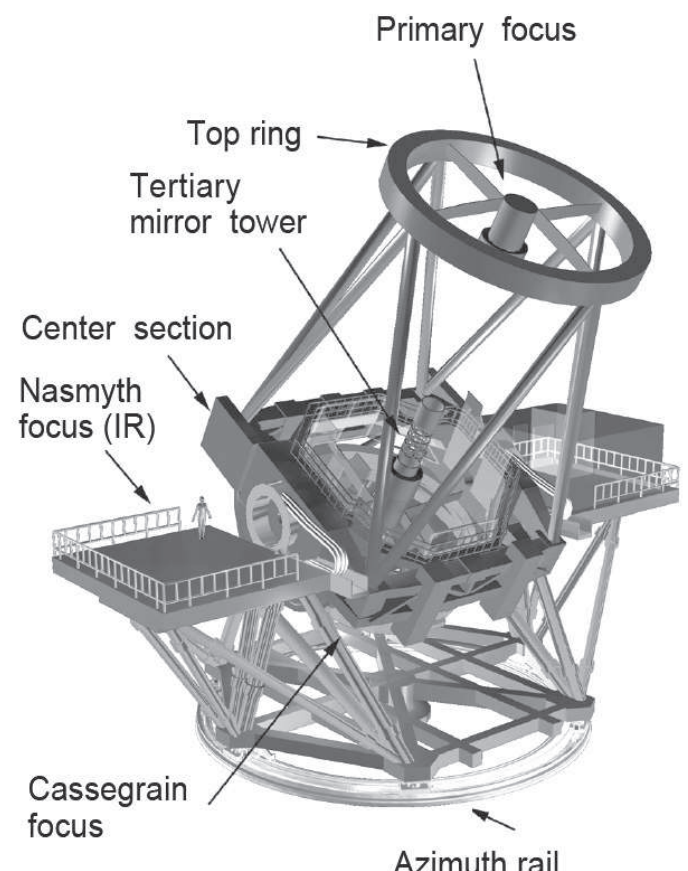

Fig. 1 Schematic of the telescope structure of the Subaru telescope. ${ }^{1)}$ 
Table 1 Specifications of the primary mirror.

\begin{tabular}{cc}
\hline Effective diameter & $8.2 \mathrm{~m}$ \\
\hline Thickness & $20 \mathrm{~cm}$ \\
\hline Weight & $22.8 \mathrm{tons}$ \\
\hline Material & ULE \\
& (Ultra-Low thermal Expansion glass) \\
\hline Focal length & $15 \mathrm{~m}$ \\
\hline
\end{tabular}

Table 2 Specifications of the telescope mount.

\begin{tabular}{cc}
\hline Mounting & Altitude-azimuth \\
\hline Optics & Ritchey-Cretian System \\
\hline Height & $22.2 \mathrm{~m}$ \\
\hline Weight & $555 \mathrm{tons}$ \\
\hline Maximum slewing speed & $0.5 \mathrm{deg} / \mathrm{sec}$ \\
\hline Open tracking accuracy & $0.1 \mathrm{arcsec}$ \\
\hline Blind pointing accuracy & $<1.0 \mathrm{arcsec}$ \\
\hline
\end{tabular}

\section{3. 観測装置}

\section{1 概要}

すばる望遠鏡では，2018年現在，以下の6つの共同利 用観測装置を運用しており，光赤外線波長域でさまざま な観測要求に対応している.

- 可視光観測装置

・超広視野主焦点力メラ $\mathrm{HSC}^{3}$

・ 微光天体分光撮像装置FOCAS ${ }^{4)}$

·高分散分光器HDS ${ }^{5)}$

- 赤外線観測装置

·多天体近赤外線撮像分光装置MOIRCS ${ }^{6}$

·近赤外線分光撮像装置IRCS ${ }^{7}$

·冷却中間赤外線分光撮像装置COMICS ${ }^{8)}$

ナスミス焦点には補償光学装置 $\mathrm{AO} 188^{9)}$ が装備され, レーザーガイド星を用いた大気摇らぎ補正を行う機能を 持つ.

上述の通り，すばる望遠鏡の特徴は他の大望遠鏡には ない広視野観測能力と高い解像度にある。以下では，こ の特徵をフルに活かした装置として超広視野主焦点カメ ラHSCと補償光学装置を取り上げる。

\section{2 超広視野主焦点カメラHSC}

超広視野主焦点カメラHSC (Hyper Suprime-Cam) は (Fig. 2), すばる望遠鏡の主焦点に装着され，およそ直 径1.5度(1.75平方度)の視野を観測できる可視光カメラで ある3)、5枚のレンズに大気分散補正系を組み合わせた 広視野補正光学系, フィルタ交換機構および検出器部か らなり, 検出器部には2000×4000画素の完全空亡型 CCDが104枚並べられている。このCCDは国立天文台が 浜松ホトニクス社と共同で開発したものであり，波 長 $0.35 \mu \mathrm{m}$ から $1.1 \mu \mathrm{m}$ までの可視光に感度を持ち, 最大 量子効率は95\%以上, $0.55 \mu \mathrm{m}$ から $0.9 \mu \mathrm{m}$ だの波長域

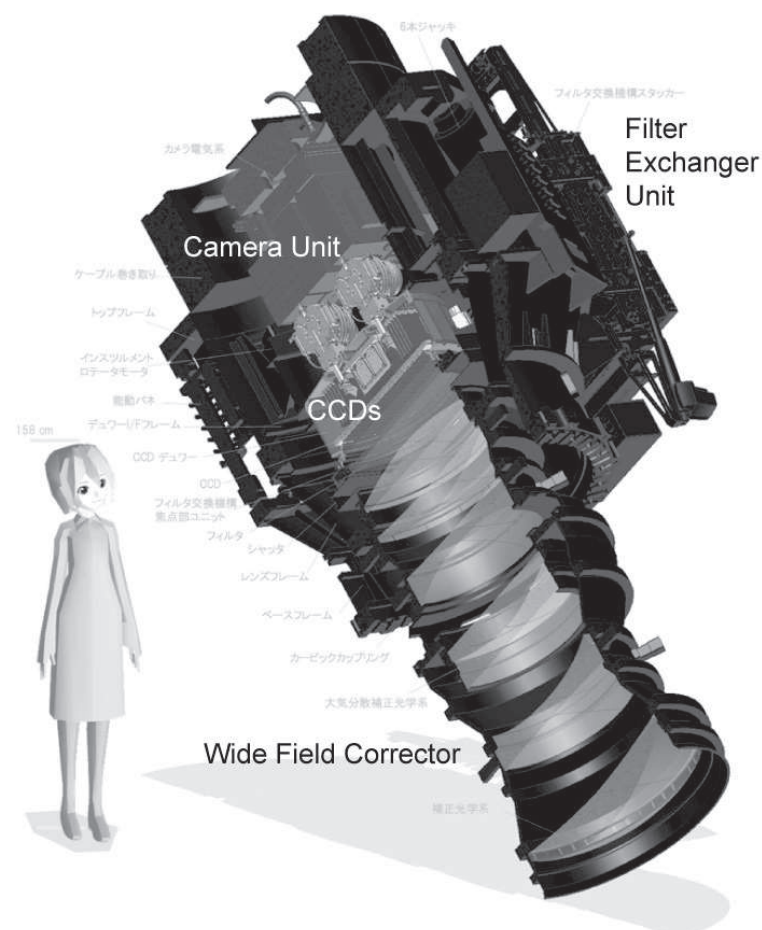

Fig. 2 Schematic of HSC.

にわたって $80 \%$ 以上の量子効率を持つ。 $\mathrm{CCD}$ の有感波長 域をカバーする $g, r, i, z, y$ の枚の広帯域フィルタと, 帯域幅 $0.01 \mu \mathrm{m}$ 程度の10数枚の狭帯域フィルタが用意さ れている.

HSCは，望遠鏡も含めた総合的な結像性能として，視 野全面に渡って星像サイズ (FWHM) が0.4秒角以下とい う值を得ている。点光源に対する限界等級 (1時間積 分, $5 \sigma$ 検出限界) は, $g$ バンド (波長約 $0.5 \mu \mathrm{m}$ )で 27.8 等 級， $i$ バンド(波長約 $0.76 \mu \mathrm{m}$ ) で26.5等級である.

HSCはその広視野撮像能力を活かして，遠方銀河探 査，重力レンズ探査，近傍銀河の広域観測，太陽系小天 体探査など, 幅広い可視光天文学分野の研究に使用され ている. 2018年現在，HSCを用いた大規模サーベイプロ ジェクトとして, HSC SSP (Subaru Strategic Program: SSP)が進行中である。HSC SSPは，5年間にわたり，す ばる望遠鏡の観測時間を300夜使用して, wide survey $(1,400$ 平方度 $)$, deep survey, ultra deep surveyの3種類の サーベイ観測を組み合わせて，広く深く宇宙を探査する 観測計画である。 wide, deep, ultra deepのサーベイ限界 等級は $g$ バンドでそれぞれ，26.5等級，27.5等級，28.1 等級である。HSC SSPは2014年からスタートし，2019年 に観測終了予定である。

\section{3 補償光学装置}

すばる望遠鏡の標準的な補償光学装置は，188素子の 可変形鏡を波面補正に用いたAO188である (Fig. 3 $)^{9,10)}$. また，ナトリウムレーザーによるレーザーガイド星シス テムも装着されている.

AO188に対応した共同利用観測装置はIRCSであり, 近赤外域(波長 $2 \mu \mathrm{m}$ ) でストレール比 0.3 程度の解像度で 


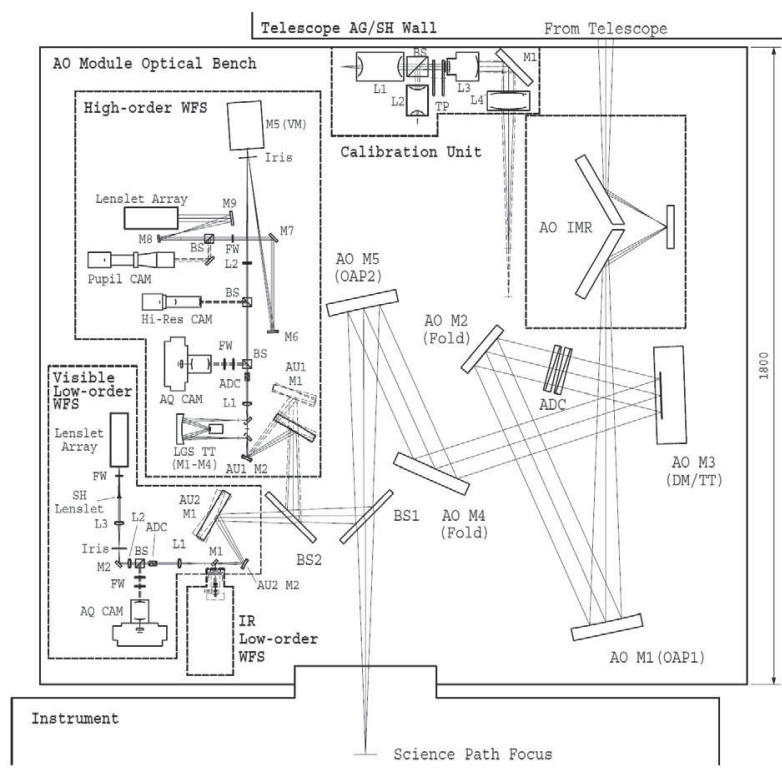

Fig. 3 Optical layout of AO188. ${ }^{10)}$

観測を行うことができている，AO188の後段には，持ち 达み装置として極限補償光学SCExAO (Subaru Coronagraphic Extreme Adaptive Optics) ${ }^{11}$ が装着され運用中であ る. SCExAOは近赤外域で回折限界に近い解像度を達成 しており(ストレール比 0.8 以上)，これを活用した観測 装置として，プリンストン大学が開発したコロナグラフ 高解像度撮像分光装置CHARIS ${ }^{12)}$ が持ち込み装置として 機能している.

$\mathrm{AO} 188$ + IRCSは, 銀河や星形成領域の高解像度観測 に盛んに利用されている。 SCExAO + CHARISは, その 高コントラスト観測性能を活かして, 系外惑星探査およ びその詳細観測に活用されている。

\section{4. 観測装置開発計画}

\section{1 赤外線ドップラー分光器IRD}

1995年に恒星の視線速度変化を精密に観測する，いわ ゆるドップラー法により, 初めて太陽系外の惑星が発見 されて以来, さまざまな観測手法により，4,000個近い 系外惑星が発見されてきた。こうした目覚ましい研究の 進展の中, 宇宙における生命探査に繋がる研究として, 地球型の惑星の探査に焦点が当たっている.

赤外線ドップラー分光器IRD (InfraRed Doppler spectrograph) は, 赤外線の高分散分光器(波長分解能 $\lambda / \Delta \lambda=$ $70,000)$ にレーザー周波数コムを組み合わせて天体分光 デー夕の高精度波長校正を行って，天体の視線速度の超 精密測定をする装置である ${ }^{13)}$ 。本稿執筆時点では調整試 験中であり，2018年後半より科学運用が開始される。

IRDの目指す速度決定精度は $1 \mathrm{~m}$ 毎秒であり, この精度 で恒星の視線速度変化を観測することで，恒星の周囲を 巡る地球型惑星を検出することを目指している。赤外線 に特化しているのは，可視光をほとんど放射しない低温 で軽い恒星をターゲットとしているからである。恒星自 身が軽いため, 地球程度の質量を持つ軽い惑星でも,
数 $\mathrm{m}$ 毎秒の視線速度変化を引き起こし, IRDで検出する ことができる。

\section{2 主焦点超広視野分光器PFS}

主焦点超広視野分光器PFS (Prime Focus Spectrograph) は，すばる望遠鏡の主焦点の視野 1.5 度 $\phi に$ 配置された 約 2,400 個の開口(光ファイバ端面)に入射した天体光を, ファイバで4つの分光器に導いて同時に分光する装置で ある (Fig. 4 $)^{14)}$. 8-10 m 級大型望遠鏡では最大の視野と 観測多重度 (同時に観測できる天体数) を持つ画期的な装 置として，遠方銀河から近傍の恒星まで様々な研究分野 で活躍することが期待されている．特に，多数の銀河の 分光データより，宇宙における銀河の分布とその進化を 明らかにして，ダークエネルギーの謎に迫ることがPFS の大きな科学的課題となっている.

PFSは，大規模な国際協力の下に開発を進められてい る. 2018年から徐々にその構成要素がハワイ観測所に到 着し，2019年から2020年にかけて組み上げ，すばる望遠 鏡への装着, 調整・試験観測が行われる予定であ る。2021年から装置が本格稼働し，共同利用に供される とともに大規模なサーベイ観測が開始される計画となっ ている。

\subsection{ULTIMATE-Subaru}

IRD，PFSに続く次世代の観測装置として，地表大気 摇らぎによる解像度の低下を補正し，広視野かつ高解像 度の近赤外線観測を実現するプロジェクト, ULTIMATE-Subaruがハワイ観測所を中心として提案されてい る ${ }^{15)}$.2026年ごろの完成を目指している。

ULTIMATE-Subaruは，すばる望遠鏡の副鏡全体を可 変形鏡とし，大気の地上層の摇らぎを補正する，いわゆ る地表層補償光学 (Ground Layer Adaptive Optics: GLAO) によって，広い視野にわたって像改善を行う。4つの レーザーガイド星を用いたトモグラフィにより，14分角

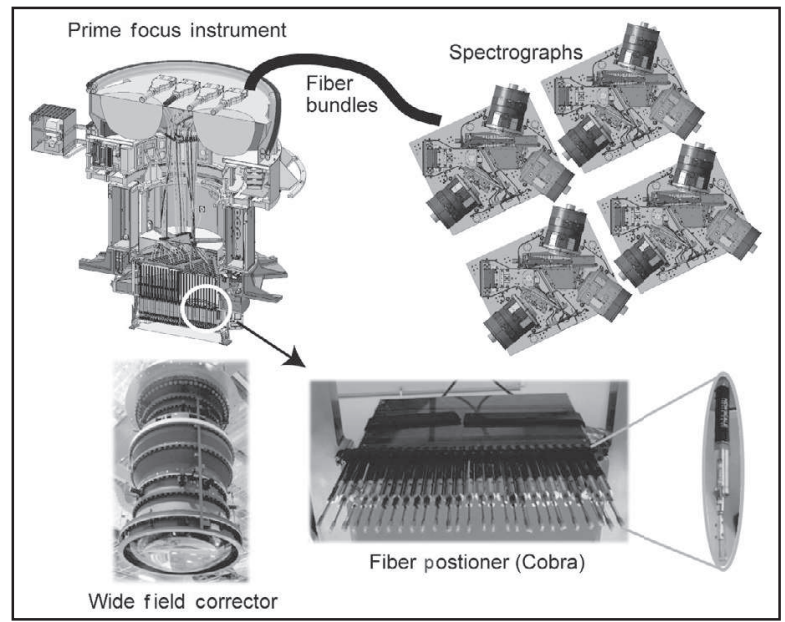

Fig. 4 Schematic of PFS. Prime focus instrument (PFI) which has 2,400 fiber positioners called "Cobra" is installed at the prime focus of the Subaru telescope. The field of view of PFI is corrected by the wide field corrector of HSC. 
の視野にわたって近赤外線で0.2秒角以下の結像性能を 達成する. ULTIMATE-Subaruの観測視野は, MOIRCS の4倍であり, 近赤外線波長域では世界の他の8-10 m 級 望遠鏡の観測装置の中では最大となる.

\section{TMT時代のすばる望遠鏡の戦略}

\subsection{TMTとすばる望遠鏡}

口径 $30 \mathrm{~m}$ のTMTは，集光力がすばる望遠鏡の約13倍 ある。望遠鏡の口径で決まる回折限界は，すばる望遠鏡 の3.6分の1であり, 補償光学が完全に機能した場合は, TMTの限界等級はすばる望遠鏡より 3 等近く深くなるこ とが予想される(点光源の場合). このような圧倒的な観 測性能の差のために, 遠方宇宙や微光天体の観測, 高解 像度・高コントラスト観測などの分野においては, すば る望遠鏡はTMTに到底太刀打ちすることはできない. 特に, 個別天体の分光観測に関しては, TMTの大きな 集光力が新しい地平を切り拓くであろう.

しかしながら, 望遠鏡の性能は単に暗いものを高解像 度で観測できる能力だけで測れるものではない。広い天 域を掃くサーベイ撮像観測においては, サーベイ観測能 力, いわゆる betendue $(\mathrm{A} \Omega=$ 望遠鏡集光面積 $\times$ 視野 $)$ と呼 ばれる指標が重要となる。Table 3 に代表的な広視野望 遠鏡のetendueを示す.TMTでは広視野可視分光器WFOS の視野が約40平方分と設計されている，仮にこの視野を 一度に撮像できたとしても, TMTのetendueは25程度で あり, すばる望遠鏡HSCの93.5にはるかに及ばない。

etendueの観点からは, 現在建設中のLSST (Large Synoptic Survey Telescope; 2023 年観測開始予定 $)^{16)}$ が圧倒的 な性能を誇るが, LSSTは南米チリに建設されており， TMTが建設される北半球においては, HSCに勝る観測 装置計画は本稿執筆現在では存在しない.さらには, LSSTは可視光の撮像能力しか持たないが, PFS, ULTIMATE-Subaruといった観測装置計画が実現すれば，すば る望遠鏡は広視野分光観測能力および広視野近赤外線観 測能力を持つことになる。 これらの能力は, LSSTと相 補的である。

\subsection{TMT時代のすばる望遠鏡の役割と価值}

TMT時代にあっては, すばる望遠鏡はその広視野観 測能力を活かして, TMTではできない観測研究を推進 していくことが使命となる，前節で述べたように，サー

Table 3 Etendue of wide-field observation facilities.

\begin{tabular}{lccc}
\hline Telescope Instrument & $\begin{array}{c}\text { Aperture } \\
(\mathrm{m})\end{array}$ & $\begin{array}{c}\text { FOV } \\
\left(\mathrm{deg}^{2}\right)\end{array}$ & $\begin{array}{c}\text { Etendue } \\
\left(\mathrm{m}^{2} \mathrm{deg}^{2}\right)\end{array}$ \\
\hline CFHT MegaCam & 3.5 & 0.9 & 8.7 \\
\hline Pan-STARRS 1 & 1.8 & 7.0 & 17.8 \\
\hline DES & 4.0 & 3.0 & 37.7 \\
\hline ZTF & 1.2 & 35.0 & 39.6 \\
\hline Subaru HSC & 8.2 & 1.77 & 93.5 \\
\hline LSST & 6.7 & 9.6 & 338.5 \\
\hline
\end{tabular}

ベイ能力においては，すばる望遠鏡はTMTを遥かに凌 いでいる。したがって，広い視野の撮像・分光観測を中 心に据え，TMTで詳細観測を実施すべきターゲットを 探査していくことが，すばる望遠鏡の主たる役割となろ う。このような動向を見据えて，ハワイ観測所では TMT完成までのすばる望遠鏡の装置整備プランを策定 している(Fig. 5)。TMT完成までに，多様な観測モード を実現する現在の観測装置群を段階的に整理し, HSC, PFS，ULTIMATE-Subaruを中心とした広視野観測機能に 重心を移していく.

TMT時代のすばる望遠鏡の役割として, 時間領域天 文学(Time Domain Astronomy: TDA) およびそれに深く関 連のあるマルチメッセンジャー天文学は極めて大きな位 置を占めることとなろう。TDAは宇宙における各種の 時間変動現象を研究する分野であり, 超新星爆発, ガン マ線バーストといった激しい爆発現象から, 系外惑星の 恒星表面通過現象まで，さまざまなエネルギースケール と時間スケールを扱う。近年, 重力波源の電磁波追跡観 測の成功 ${ }^{17)}$ 受け，電磁波のみならず，重力波や粒子観 測まで含めたマルチメッセンジャー天文学が注目を集め ているが, その対象となる現象は, ブラックホール合体 や中性子星合体といった激しい時間変動を伴う。こうし た現象はいつどこで起きるか全く予測不可能なため，そ の探査と追跡には，機動性に富む広視野観測装置が必要 となり，特に現象の初期段階の迅速な観測は，TMTに は困難であることが予想される。TMT時代のすばる望 遠鏡には，その広視野観測能力を活かし，現在よりも機 動的な運用体制を敷いて, TDAおよびマルチメッセン ジャー天文学を強力に推進し, TMTとの相補的役割を 果たすことも期待される.

TMT時代において，単にTMTのターゲット選択をす るに留まらず, TMTでカバーできない幅広い研究分野 を推進していくために，8-10 m級の広視野望遠鏡の重 要性はますます高まると思われる。このことは, 8-10 m望遠鏡時代にあって，世界の4 m 級望遠鏡が果た している役割を見れば明らかである．現在，多くの $4 \mathrm{~m}$ 望遠鏡が広視野観測能力を備え, 大規模なサーベイ観測 を実施している。そして，8-10 m望遠鏡を凌ぐような 科学的成果を挙げている. TMT時代のすばる望遠鏡の 姿を, 今の 4 m級望遠鏡の活躍に重ねて見ることは，あ ながち，穿ちすぎた見方ではないであろう。

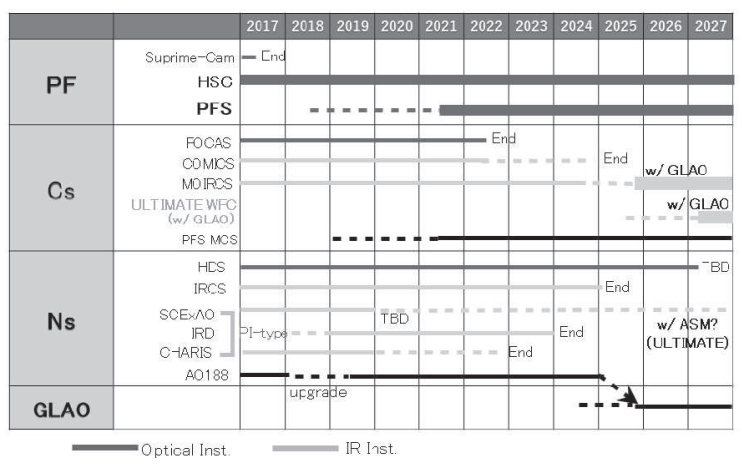

Fig. 5 Instrumentation plan of the Subaru telescope. 


\section{6. まとめ}

すばる望遠鏡は，現在，多様な観測装置を備え，それ らを用いて，太陽系から遠方銀河，宇宙論に至るまで， 最先端の光赤外線観測研究が進められている。すばる望 遠鏡の広視野観測能力は，他の8-10 m望遠鏡にはない 特徴であり，しかもそれを高い解像力で実現している。 TMTの活躍する時代には，すばる望遠鏡の広視野観測 能力は，TMTのサイエンスを支え，TMTによる詳細観 測・深宇宙探査と相補的な役割を果たすとともに, TMTでは実現が困難な観測テーマを推進していくため のキーとして，ますますその存在感および重要性を増す であろう。

\section{参考文献}

1) M. Iye, H. Karoji, H. Ando, N. Kaifu, K. Kodaira, K. Aoki, W. Aoki, Y. Chikada, Y. Doi, N. Ebizuka, et al.: Publ. Aston. Soc. Jpn. 56 (2004) 381

2) N. Kaifu, T. Usuda, S. Hayashi, Y. Itoh, M. Akiyama, T. Yamashita, Y. Nakajima, M. Tamura, S. Inutsuka, M. Hayashi, et al.: Publ. Astron. Soc. Jpn. 52 (2000) 1.

3) S. Miyazaki, Y. Komiyama, S. Kawanomoto, Y. Doi, H. Furusawa, T. Hamana, Y. Hayashi, H. Ikeda, Y. Kamata, H. Karoji, et al.; Publ. Astron. Soc. Jpn. 70 (2018) S1.

4) N. Kashikawa, K. Aoki, R. Asai, N. Ebizuka, M. Inata, M. Iye, K. S. Kawabata, G. Kosugi, Y. Ohyama, K. Okita, et al.: Publ. Astron. Soc. Jpn. 54 (2002) 819

5) K. Noguchi, W. Aoki, S. Kawanomoto, H. Ando, S. Honda, H. Izumiura, E. Kambe, K. Okita, K. Sadakane, B. Sato, et al.: Publ. Astron. Soc. Jpn. 54 (2002) 855.
6) R. Suzuki, C. Tokoku, T. Ichikawa, Y. K. Uchimoto, M. Konishi, T. Yoshikawa, I. Tanaka, T. Yamada, K. Omata and T. Nishimura.: Publ. Astron. Soc. Jpn. 60 (2008) 134.

7) N. Kobayashi, A. T. Tokunaga, H. Terada, M. Goto, M. Weber, R. Potter, P. M. Onaka, G. K. Ching, T. T. Young, K. Fletcher, et al.: Proc. SPIE 4008 (2000) 1056.

8) H. Kataza, Y. Okamoto, S. Takubo, T. Onaka, S. Sako, K. Nakamura, T. Miyata and T. Yamashita: Proc. SPIE 4008 (2000) 1144.

9) Y. Hayano, H. Takami, O. Guyon, S. Oya, M. Hattori, Y. Saito, M. Watanabe, N. Murakami, Y. Minowa, M. Ito, et al.: Proc. SPIE 7015 (2008) 10

10) Y. Hayano, H. Takami, S. Oya, M. Hattori, Y. Saito, M. Watanabe, O. Guyon, Y. Minowa, S. E. Egner, M. Ito, et al.: Proc. SPIE 7736 (2010) 21.

11) N. Jovanovic, F. Martinache, O. Guyon, C. Clergeon, G. Singh, T. Kudo, V. Garrel, K. Newman, D. Doughty, J. Lozi, et al.: Pub. Aston. Soc. Pacific 127 (2015) 890.

12) T. Groff, J. Chilcote, T. Brandt, N. J. Kasdin, M. Galvin, C. Loomis, M. Rizzo, G. Knapp, O. Guyon, N. Jovanovic, et al: Proc. SPIE 10400 (2017) 16.

13) T. Kotani, M. Tamura, H. Suto, J. Nishikawa, B. Sato, W. Aoki, T. Usuda, T. Kurokawa, K. Kashiwagi, S. Nishiyama, et al.: Proc. SPIE 9147 (2014) 14.

14) N. Tamura, N. Takato, A. Shimono, Y. Moritani, K. Yabe, Y. Ishizuka, A. Ueda, Y. Kamata, H. Aghazarian, S. Arnouts, et al.: Proc. SPIE 9908 (2016) 1M.

15) Y. Hayano, M. Akiyama, T. Hattori, I. Iwata, T. Kodama, O. Lai, Y. Minowa, Y. Ono, S. Oya, K. Takiura, et al.: Proc. SPIE 9148 (2014) 2S.

16) Z. Ivezic, J. A. Tyson, B. Abel, E. Acosta, R. Allsman, Y. AlSayyad, S. F. Anderson, J. Andrew, R. Angel, G. Angeli, et al.: arXiv 0805.2366 (2008).

17) B. P. Abbott, R. Abbott, T. D. Abbott, F. Acernese, K. Ackley, C. Adams, T. Adams, P. Addesso, R. X. Adhikari, V. E. Adya, et al: Astrophys. J. Lett. 848 (2018) L12. 